\title{
Blunt Cerebrovascular Artery Injury and Stroke in Severely Injured Patients: An International Multicenter Analysis
}

\author{
Ajay Malhotra ${ }^{1} \cdot$ Xiao $\mathbf{W u}^{1} \cdot$ Kimberly Seifert $^{1} \cdot$ Long Tu $^{1}$
}

Published online: 30 January 2018

(C) Société Internationale de Chirurgie 2018

\section{Dear Editor,}

We would like to commend the authors Weber et al. [1] for their study assessing BCVI and stroke in such a large series of patients. However, we have a few questions and concerns about the study.

Computed tomographic angiography (CTA) was applied for primary blunt cerebrovascular injury (BCVI) screening, but the authors do not specify whether all 76,480 individuals received a CTA study. If not, what criteria were used to screen patients with CTA? The conclusions drawn about the utility of screening criteria in predicting BCVI would be valid if all patients were screened. Retrospective analysis of risk factors may not be an accurate method if all patients were not consistently screened.

The literature is very heterogeneous about the sensitivity and specificity of CTA, and different studies advocate conventional angiography in CTA-negative and CTApositive patients, respectively $[2,3]$. We would request the authors to comment on the use of conventional angiography in their dataset. The reported incidence of BCVI in the literature is reflective of not only the screening criteria used, but also the sensitivity of the imaging used to screen patients.

It would also be helpful to know from the authors the use of medical prophylaxis in both screened and unscreened patients. 30/58 strokes in this study happened despite prophylaxis, and 10/58 happened before start of therapy. The utility of screening criteria and CTAs has to be seen in the context of use of subsequent treatment and thereby prevention of stroke.

Greater awareness of BCVI, the grading of injury and imaging pitfalls would help improve noninvasive imaging diagnosis [4]. Optimized, selective CTA in high-risk populations may be the most cost-effective strategy for BCVI detection [5].

\section{References}

1. Weber CD, Lefering R, Kobbe P et al (2017) Blunt cerebrovascular artery injury and stroke in severely injured patients: an international multicenter analysis. World J Surg. https://doi.org/10. 1007/s00268-017-4408-6

2. Paulus EM, Fabian TC, Savage SA et al (2014) Blunt cerebrovascular injury screening with 64-channel multidetector computed tomography: more slices finally cut it. J Trauma Acute Care Surg 76(2):279-283 (discussion 284-275)

3. Grandhi R, Weiner GM, Agarwal N et al (2017) Limitations of multidetector computed tomography angiography for the diagnosis of blunt cerebrovascular injury. J Neurosurg. https://doi.org/10. 3171/2017.2.JNS163264

4. Wu X, Malhotra A, Forman HP, Nunez D, Sanelli P (2017) The use of high-risk criteria in screening patients for blunt cerebrovascular injury: a survey. Acad Radiol 24(4):456-461

5. Malhotra A, Wu X, Kalra VB, Schindler J, Matouk CC, Forman HP (2016) Evaluation for blunt cerebrovascular injury: review of the literature and a cost-effectiveness analysis. AJNR Am J Neuroradiol 37(2):330-335
Ajay Malhotra

ajay.malhotra@yale.edu

1 Diagnostic Radiology, Yale School of Medicine, New Haven, CT, USA 